\title{
Commutes and co-workers: Complicating individual journeys through workplace relations
}

\begin{abstract}
The everyday mobilities involved in performing paid work have increasingly been conceptualised in relation to their social context, with transport researchers seeking to move away from a view of the commuter as a solitary figure driven by a utility-maximisation rationale. To date, most research which emphasises the social embeddedness of commutes has focused on the ways in which gender, class and race shape commuting experiences, and the role of household relations in the organisation of the commute. In this paper, I contribute to this body of work by exploring the links between the commute and the social relations of the workplace. The paper draws on qualitative data collected among commuters in Sofia, Bulgaria, and includes both office workers and people employed in shift work in the tourism and hospitality sector. The findings discuss the multiple ways in which formal and informal workplace interactions become part of everyday journeys, whether through commuters arranging to travel together, through strategies for avoiding co-workers on the way to work, or through managerial measures aiming to shape commutes. Commuting experiences, in turn, are not external to the workplace but are woven through it in a range of ways, as co-workers discuss commuter stress, or set time aside to plan easier, safer or more affordable travel to work.
\end{abstract}

\section{Introduction}

Numerous contributions to mobilities and transport research have challenged the view of the commute as individualist, functionalist movement from A to B, performed by a solitary rational subject. From various disciplinary perspectives, notably those originating in feminist geography and time geography, an alternative view of the commute has emerged, as an everyday journey embedded in complex webs of social relations (Beige and Axhausen, 2012; Bissell, 2018; Pratt and Hanson, 1993). As Laurier et al. (2008:2) point out, the relations which make up everyday life are not 'suspended' while commuters travel between origin and destination. Connections to others continue to be felt, made, made sense of, and transformed, both among those co-present during the commute, and between commuters and people elsewhere. Nevertheless, understandings of how social relations shape commuting, and the ways in which commuting shapes them in turn, remain limited. To the extent that this line of enquiry has been pursued, it has focused predominantly on the negotiation of the broad social categories of gender, class and race, and above all on the influence of household relations (Hanson, 2010; Lanzendorf, 2010; Pooley et al, 2011; Plyushteva and Schwanen, 2018). The interdependencies between people and their kin have been demonstrated to shape commuting to a great extent, as household members continuously arrange and re-arrange mode, time, duration, route, in order to combine competing priorities including work, education, care, and leisure (Pratt and Hanson, 1991; Rau and Sattlegger, 2018; Schwanen, 2007). However, other types of social relations which shape commuting have not been explored in detail, including those which relate to work and workplaces.

Workplace mobility plans are among the few forms of influence of workplace relations on commuting which have been addressed in transport and mobilities research (Roby, 2010). However, research in this field is frequently limited to positivist and normative understandings of how the workplace shapes everyday mobility. Scholarship in this vein tends to be orientated towards identifying effective interventions for changing commuter behaviours, and frequently overlooks the diversity of ways in which workers' mobilities and social relations interact. In the 
case of the reverse - how the commute influences the workplace - studies have mostly focused on the impact of commuter stress on work performance and worker well-being (Wener et al., 2003). The role of the everyday journey to work as an aspect of workplace social relations is less well understood. In this paper, I contribute to theorising the commute in its social context by examining a more diverse and contingent set of links between workplace relations and commuting practices. My aim is to demonstrate that a) workplace relations shape commutes in a broader range of ways than is often acknowledged, and b) the commute in turn shapes the workplace and workplace social relations.

The paper brings together data from two research projects, conducted between 2012 and 2018, which explored different aspects of commuting in Sofia, Bulgaria. I draw on these data to explore the way relations at work become part of the commute, and influence experiences of both travel and work. In doing so, I aim to show that the commute is not a timespace external to workplace relations or, as it is traditionally framed, as that which links the home and the place of work, as if they are separate social domains and spatio-temporal containers. By tracing workplace social relations from and to the journey to work, it is possible to identify the multiple connections which exceed compartmentalised definitions of work and mobility. Thus, the paper frames workplace social relations as enacted, reconfigured and problematised through work-related everyday journeys - and vice-versa.

The next section provides an overview of the transport and mobilities research on commuting, workplaces, and social relations, which informs the conceptual framework of the paper. Section 3 presents the methodological approach used in the studies on which this paper draws, and also gives a brief introduction to urban and mobility issues in contemporary Sofia. The main body of the paper is organised into three themes. The first focuses on the range of ways in which hierarchical relations between workers and managers are negotiated in the commute. The second examines the practices which co-workers deploy in order to travel to work together, or alternatively, to avoid travelling together. The third theme of the findings section looks at commuter stress and strategies for reducing it as vehicles through which commuter journeys become part of social interactions in the workplace. The final section discusses the broader implications of the findings and offers some concluding remarks.

\section{Theoretical framework}

\section{2-1. Commuting and social relations}

Contemporary mobilities and transport research has proven relatively influential in countering the view of travel time, and particularly commuting time, as nothing but time lost. A number of studies from a range of contexts and adopting diverse methodological approaches have shown the commute to be a site in which identities, habits and relations are enacted and continuously reshaped, just like they are in stationary settings like homes, offices, factories and parks (Adams, 1981; Bissell, 2018; Laurier and Lorimer, 2012; Wilson, 2011). A growing number of studies have focused in particular on theorising the way household relations are not only present in everyday journeys but also shape them to a significant extent. Time geography and feminist geography have been particularly important in this context, as they frame everyday activities (including travel) in terms of intricately and continuously woven connections to people and places, and not as the outcome of utility-maximising decisions of individuals (Ellegård and Svedin, 2012; Hagerstrand, 1973; Pratt and Hanson, 1993; Thrift and Pred, 1981; Wheelock and Oughton, 1996).

Research in this vein examines, for example, the ways in which at different times over the lifecourse, significant others and shared responsibilities influence the individual commuter's route, transport mode, journey duration and transport costs (Chatterjee and Scheiner, 2015; Döring et al., 2014; Jarvis, 1999). This empirical and theoretical focus on household relations has gone some way towards disrupting the figure of the solitary, rational commuter which dominates transport planning and policy (Adams, 1981; Manderscheid, 2013). Research on the way household relations shape commuting reveals the organisation of mundane journeys to be anything but 
mundane: it involves continuous re-negotiation of work, care, resources, emotions and meanings in ways which are complex, sometimes discordant, and always gendered (Gil Solá, 2016; Schwanen, 2007).

Research on commuting and household relations has made many important contributions to the study of everyday mobility, but two are especially relevant here. First, they have spurred the retheorisation of the solitary utility-maximising 'transport user,' and a recognition of travel behaviours' capacity to reflect, produce and re-shape social embeddedness and social roles (Hamilton and Jenkins, 2000). Second, studies such as that of Gil Solá (2016) have demonstrated that in organising their commutes, household members are not driven by a shared goalorientation, but rather household mobility arrangements reflect complex negotiations which involve tensions, compromises, conflict and power, as well as ingrained ideas about gender roles, childcare, and so on (see also Law, 1999).

Further work is needed in order to expand this body of work into a comprehensive account of the embeddedness of the commute in social relations, for two main reasons. First, household relations are only one type of relationship which manifests itself in everyday mobility practices, and there is a need to attend also to those social relations which emerge from paid employment, unpaid work, friendship, religious and civic links, among others. Second, the workplace has been recognised in transport research as a key element in transport policy and planning efforts to reduce the harmful impacts of commuting. At the same time, theoretical engagements with the specific ways in which the commute and the workplace are interlinked, remain scarce. Understanding the many dimensions of these linkages is an important step towards conceiving better measures for reducing the social and environmental impacts of commuting, as well as towards recognising the limitations of such measures.

\section{2-2. Workplace relations and commuting}

Workplace relations are generally defined as the social relations among people engaged in paid work together, including informal and formal interactions with supervisors, peers, subordinates and customers (Collins et al., 2016; Pettinger, 2005). They are also not necessarily a separate category to other types of social relations; kinship and friendship relations are part of work life for many people (Pettinger, 2005). Another important caveat to highlight here is that this paper's focus on paid employment implies a narrow view of work and workplaces, since work includes a range of informal, unpaid, voluntary and domestic labour (McDowell 2008:492).

The ways in which the social relations in and of the workplace emerge, fluctuate, and are sustained, can have profound implications for everyday life and well-being. Some of the dimensions which researchers have explored include the impact of workplace relations on learning and professional development, earnings, experiencing friendship and belonging, and navigating social identities (Berman et al., 2002; Roy, 1959). Employment research has argued that positive workplace relations can enrich jobs, ensure job satisfaction, and boost individual and organisational achievement, while negative experiences of workplace social relations cause stress, reduce well-being and lead to increased staff turnover (Collins et al., 2016; Pettinger, 2005; Sias, 2012). However, reliance on positivist definitions of 'positive' and 'negative' has underplayed the complexities of social interactions related to work, and added to a compartmentalised view of the workplace as a separate social sphere.

The ways in which workplace relations may shape and re-shape the organisation of the commute in a similar manner to household relations, remains unclear. To the extent that this link has been examined, this has focused on formal workplace mobility plans, and their - often limited capacity to trigger behaviour change among employees to promote sustainable commuting practices (Van Malderen et al., 2012). It is generally assumed that the organisation of the commute, at least to some extent, is a reflection of spatial, temporal and economic constraints directly imposed by employers and managers, as well as the specific demands of a job itself (Ge et al., 2018; Jirón and Imilan, 2015; Schwanen, 2006: 891). Indeed, it can be expected that whether a commuter catches a particular train, or leaves work at a particular time, is at least partly the 
result of explicit demands placed upon them in terms of work and working hours. In practice, this direct causal link between workplace requirements and commuter travel behaviours is likely to be complicated and modified in numerous ways. Increasingly, research on commuting has demonstrated the fuzzy (for some) nature of the spatio-temporal constraints the workplace imposes on the journey to work: more flexible working hours and remote working are expected to relax the grip that the nature of employment has on how daily travel is negotiated (Ben-Elia and Ettema, 2011; Shen et al., 2013). However, there are two limitations to this. First, it applies to some, but not all jobs, and the dominance of this narrative in mobilities research often risks making the experiences of commuters who are not office workers invisible (Plyushteva, 2018). Second, it assumes that what happens in the workplace manifests in the commute as identifiable spatial and temporal constraints. By contrast, focusing on the relations which take place in but also extend out of workplaces allows for a more nuanced understanding of how the workplace becomes 'present' in the commute. This relational lens does not assume that constraints on and capacities for everyday mobility are the direct result of superiors' orders or contractual obligations, but rather reflects the idea that this link may in some cases be more malleable and open-ended than previously acknowledged.

\section{2-3. Commuting with others}

Research on the social embeddedness of commuting complements, but stands somewhat apart from, mobilities research on the embodied and situated practices of commuting. Transport and mobilities scholars have challenged the view that the commute is empty time, and have demonstrated that being on the move can involve activities which are as diverse and as meaningful as those which take place at origin and destination (Jain and Lyons, 2008; Lyons and Chatterjee, 2008: 190). This has informed a range of in-depth examinations of the practices, objects, atmospheres and meanings involved in the seemingly mundane and uniform activities of commuting (Bissell, 2010; Jirón et al., 2016; Middleton, 2011; Vannini, 2011).

Mobilities research has made an important contribution to our understanding of the social interactions, whether verbal or not, which are abundantly present in the commute. These interactions are very diverse, from drivers yelling at cyclists who slow down traffic (Nixon, 2014), to train passengers exchanging brief greetings (Bissell, 2018) or making room for each other (O'Dell, 2009), to metro passengers scrutinising the behaviours of others and occasionally reprimanding them for it (Plyushteva, 2019). While most of these interactions are too fleeting to be termed social relations, they are consequential for experiences of daily mobility (Wilson 2011). However, social relations have rarely been the focus of this type of mobilities research, which prioritises either the embodied experiences of individual commuters, or the more subtle and fleeting atmospheres which circulate between commuting strangers.

A small number of studies has also looked at the social relations of co-present commuting. In a notable example, Laurier et al. (2008) examine the minute, situated interactions involved in sharing car space: what they refer to as driving and 'passengering' together. The authors highlight that both household and workplace relations are enacted in the confined space of the car, in ways which differ from interactions at home or at the office, but are no less significant. These relations are in turn influenced by what happens during the commute, as in the example of carpooling colleagues discussing whether to complain about another co-worker (Laurier et al., 2008: 18). The authors distinguish between the two types of relations and the resulting shared journeys; one of the starkest differences is that among carpooling colleagues, the driver assumes the role of 'host,' while the others use verbal and non-verbal cues to act as considerate 'guests' (Laurier et al., 2008: 15). The relation of sharing a commute requires care and maintenance, particularly when it comes to the extent it influences, and is influenced by, what happens in the workplace. As the authors found, travelling with co-workers can be a way of reducing costs or travel time, managing other aspects of the commute, and can also serve as an additional, and more private, space in which to discuss work. This can make a positive contribution to one's work, help cultivate better working relationships and friendships, but it can also create tensions and complications, making the commute more tiring than it would be otherwise (Laurier et al., 2008). These insights 
point to the many possible frictions and complexities which can ultimately impede the capacity of interventions like formal workplace mobility plans to promote practices such as carpooling.

Importantly, the workplace does not shape the commute only when co-workers share the journey itself. As with household relations, mundane journeys can be thought of as the enactment of relations in time and space, even when journeys are undertaken separately (Plyushteva and Schwanen, 2018). In the case of households, expectations placed by others, their needs, care for them, shared as well as competing household responsibilities, are all folded into the seemingly simple act of travelling to work and back. In a similar way, workplace relations can manifest themselves in the organisation of the commute without physical co-presence, as the discussion below demonstrates.

\section{Research methods and location}

\section{3-1. Methods}

The first project I draw on in this paper is my doctoral research, which involved a qualitative longitudinal exploration of the impact on commuters' everyday practices of the opening of a new metro line in Sofia, Bulgaria (Plyushteva, 2016). Data collection took place between 2012 and 2015 , and combined go-along interviews with thirty-one commuters, twenty of whom were interviewed between six and eight times over the course of at least ten months, in order to capture change in everyday commuting practices over time.

In addition, the paper draws on qualitative data from a research project which explored formal and informal workplace mobility planning in the context of shift work in the tourism and hospitality sector (Plyushteva, 2018). Methodologically, this research combined a short online questionnaire followed by in-depth qualitative interviews. The data from this project used in the present paper include in-depth interviews with 12 employees and 9 employers, conducted in Sofia in 2017 and 2018.

While neither of the two project addressed links between workplaces and commutes from the outset, the theme emerged inductively from the data collected as research participants repeatedly discussed workplace interactions and social relations when describing their commuting arrangements and the way they negotiated the everyday mobility challenges they faced. While reanalysing previously collected commuting data from the perspective of workplace relations inevitably has limitations, the diversity of workplaces and participants included in the project, and the longitudinal nature of the data, allow me to begin unpacking a little-researched subject.

Transport research has often been overly reliant on the 9-to-5 office worker commute, which is often implicitly or explicitly taken to define most commuting experiences. The discussion presented here draws on data relating to both 9-to-5 and shift work commutes, including night shift commutes. In the discussion that follows, I aim to present empirical data in ways which make explicit aspects of participants' commutes which may otherwise be taken for granted. These include, for instance, whether the commute takes place during the morning and evening rush hours, whether the commute is a predictable and repetitive journey, and the transport mode(s) commuters rely on.

\section{3-2. Research location}

\section{[Figure 1 approximately here]}

Sofia is the capital city of Bulgaria and has approximately 1.4 million inhabitants (Eurostat, 2018a). The population of Sofia has been on the increase since the early 2000s, as the concentration of economic opportunities in the capital has attracted significant internal migration (Eurostat, 2018b; National Statistics Institute, 2019).

Since the collapse of state socialism in 1989, the city has witnessed extensive and often turbulent socio-economic change, and these processes have had profound impacts on urban form and 
mobility. Notably, Sofia has suburbanised and extended beyond the historical spatial boundary of the ring road (Figure 1), and peri-urban development has in turn resulted in greater residential segregation and increased commuting distances and reliance on car transport among the suburbanising middle- and high-income households (Hirt, 2012). A related process is the spatial reorganisation of workplaces, as Sofia's economy has moved away from the heavy and light industries which dominated it in the $20^{\text {th }}$ century, becoming more diverse and incorporating rapidly developing IT (10\% of employed people in 2017) and tourism (4.3\% of employees) sectors (National Statistics Institute, 2019).

[Figure 2 ( $\mathrm{a}$ and $\mathrm{b}$ ) approximately here]

The proliferation of tourism and hospitality enterprises has transformed Sofia's dense historical centre, which lost many of previously abundant affordable homes, resulting in longer commutes also for lower-income workers employed in tourism, hospitality, cleaning and other service sectors in the urban core (Barnfield, 2016; Roelofsen, 2018). At the same time, the Southern urban edges have seen a surge in the number of business and technology parks, where large ITsector companies in particular are concentrated (see Figure 2a). Commanding some of the highest salaries, these workplaces are often cut off from urban amenities, and served by relatively less frequent public transport. These dynamics have contributed to growing automobility and its detrimental social and environmental effects. Increases in car ownership show no signs of slowing down, with the number of newly registered cars growing from 385 per 1,000 population in 2006 to 552 per 1,000 in 2016 j).

\section{[Figure 3 approximately here].}

Public transport, already in a steady decline since the 1960s, saw further cuts in funding amid the post-1989 economic crisis. Its modal share dropped from $64.7 \%$ in 2000 , to $49.0 \%$ in 2009 , and to $37.0 \%$ in 2017 (Mott Macdonald, 2011:19; see Figure 3). On one hand, Sofia's network of bus, trolleybus, tram, and increasingly metro, is extensive (with $2,055 \mathrm{~km}$ of bus lines, $146 \mathrm{~km}$ of tram tracks, $99 \mathrm{~km}$ of trolleybus lines and $29 \mathrm{~km}$ of metro lines in 2014, National Statistics Institute, 2016). On the other hand, antiquated rolling stock can still be seen on most lines, with services relying on an obsolete ticketing system, and roads, transport stops and pedestrian underpasses in a poor condition. As a result of years of neglect, ridership figures saw a steady decline, with the annual number of bus journeys falling by $20 \%$ between 2011 and 2014 (Vision for Sofia, 2018). In addition, traffic congestion from growing numbers of private cars has brought down the average operational speed of buses, which fell to $18.3 \mathrm{~km} / \mathrm{h}$ in 2016, as well as resulting in air pollution, a surge in traffic-related injuries, and reduced quality of the public realm associated with the dominance of moving and parked cars (Barnfield and Plyushteva, 2016; Grozdanov, 2011; Mott Macdonald, 2011; Vision for Sofia, 2018; see Figure 2b). While cycling has experienced a modest resurgence since the early 2010s, safe cycling infrastructure remains scarce, and the bicycle's modal share remains modest at just over 1.5\% despite its increased visibility in the city's streets and public debate (Barnfield and Plyushteva, 2016; Sofia Municipality, 2016).

Since 2012, the city has seen some modest improvements in public transport infrastructure, notably through investment in rolling stock and a programme of expanding the metro network (a second line was added in 2012, and a third is due to open in late 2019). Some evidence suggests a slow move away from the cultural framing of the private car as a key signifier of personal success (a shift also observed elsewhere, see Chatterjee et al., 2018). Commitment to public transport was reaffirmed to some extent in 2018, with the launch of a night bus network and a gradual renewal of the rolling stock. However, the social and environmental impacts of transport, and of the everyday commute in particular, continue to be hotly debated, with many researchers 
and commentators identifying the journey to work as a major strain on quality of life and wellbeing for Sofia's inhabitants (Vision for Sofia, 2018).

\section{Findings}

\section{4-1. The negotiation of workplace hierarchies within the commute}

To date, research on workplaces and commutes has predominantly explored the punctuality demands which some employers and types of work place on some workers, while others have increasingly flexible working hours and thus greater independence in planning and adjusting their commuting arrangements. More recently, research has focused on formal measures which employers have taken to reduce the environmental impact of commuting and its economic cost, through workplace sustainable mobility plans (Cairns et al., 2010; Enoch, 2012; Roby, 2010). However, research on workplace mobility plans tends to be normative in nature, evaluating the ability of measures to achieve particular environmental goals, such as reducing the share of workers who travel to work by car. This focus on behaviour change has meant that the mechanisms through which employers use incentives and disincentives to influence the travel of workers, are rarely scrutinised. In practice, the ability of employers and managers to intervene in the commute reflects the limitations of what is often assumed to be a palpable boundary between the workplace and private life (Cohen, 2008).

In addition, employers' roles in the organisation of workers' everyday travel are not limited to formal measures, but can be multifaceted and significant even without being formalised. The following comments made by one employer, interviewed on the theme of workplace mobility planning, illustrates this:

AP: Do you have to offer any kind of assistance with the employees' commute to work, given that the restaurant is not very easy to get to?

Alan: Not really. I have always worked in places with strict discipline, and I also manage this place with strict discipline. People expect too much to be provided for them, instead of taking care of themselves. I want the people who work here to come to work with me because they want to, because they want the experience, to learn a craft. I don't want them to expect help with finding a way to get here. I never expected help from anyone when I was working in other people's kitchens. (...) I think staff value having the opportunity to work here with me. (Alain, chef and restaurant owner, variable hours, drives to work, interviewed May 2017)

This comment demonstrates how authority figures can see individuals' organisation of their commute as a marker of motivation and commitment. The restaurant, located on the Southern outskirts of the city, was poorly served by public transport, particularly after $10 \mathrm{pm}$, and the shifts of both front-of-house and kitchen staff working during the evening service finished after that hour. However, for this employer, employees' ability to cope with the challenge of the journey contributed to his assessment of how hard they were willing to work.

On the face of it, a small workplace with tight-knit relations and no formal mobility plan can appear free from hierarchical authority and formal enforcement of mobility-related measures. In practice, the power of employers and managers to make particular kinds of journeys the norm is present, but operates in slightly different ways to the plans and procedures of large organisations. This is illustrated in the following two interview excerpts, one from an interview with the owner/manager of a bar, and the other contributed by a waiter in a restaurant:

Ifyou're a more junior, less experienced member of staff, you are paid less. So, we will always try and give you a lift home. This is not a formal arrangement. (...) But we are a very small team, we all know where people live, how everyone travels here and back. If someone drives, they will offer a lift to another. We just talk to each other, we are a very close team, and we just make it work. (Anya, bar owner/manager, works from $5 \mathrm{pm}$ until closing time, walks/drives to work, interviewed June 2017) 
Occasionally, the manager gives people a lift, and since I live on her route, she drops me off, which is great for me. However, this is not anything that is organised systematically: if it happens, great, if not, I have to fend for myself. (Julia, restaurant waiter, varying shifts and transport modes, interviewed June 2017)

The two quotes above come from different workplaces yet illustrate two contrasting perspectives on a similar commuting arrangement. For Anya, the informal and ad-hoc approach to organising transport at the end of a late shift is something that is just 'made to work.' However, for Julia, who works in a restaurant where the manager takes a similar approach, this type of arrangement means that she has no control or advance knowledge over her trip home. She does not find out whether a lift home will be available until the end of the shift, when she has to adapt her commute to the plans the manager has on a particular day. In both cases, the people in managerial positions, who are also often those driving private cars, reinforce workplace hierarchies through the commute in subtle ways, even though they are not implementing any formal mobility measures.

Only two of the Sofia workplaces studied had formal commuting plans in place, insofar as they had written documents covering multiple mobility measures, aimed at tackling specific objectives. Both workplaces were large IT companies. With the IT sector in Sofia booming since the early 2010s and staff shortages increasingly common, these employers had to make the commute an explicit part of a considerate and accommodating workplace:

In the current office, I have to find my own space in the building parking lot. I have to pay for [the use of the parking], and then I get reimbursed. It's never a problem to find free space there, but obviously, it's never the same one. So, it's never just outside the elevator doors. But there are rumours we'll be changing the office to a bigger building (...) But it's important that the office is in the same area, as the owners fear they will lose employees if there is a radical change in the location. The employees in this sector are in a very strong position. (Julian, software developer, mostly works $10 \mathrm{am}$ to $7 \mathrm{pm}$, drives to work, interviewed January 2015)

The dynamics of workplace organisation in the IT sector as explicated by Julian, were an example of formal workplace hierarchies being made less stable within the arrangements of commuting. While employers and managers had authority regarding day-to-day job tasks, recruitment and promotion, and many other aspects of work, retaining employees in this sector was seen as contingent on visible efforts to accommodate worker preferences, including commuting preferences. Discouraging driving to work was rare in this sector, due to, on one hand, the peripheral location of most IT companies' offices, which gave them relatively greater access to space, and on the other hand, the imperative of not inconveniencing employees who are "in a very strong position." This process has clear implications for the spatial distribution of IT sector work, highlighting the way commuting has shaped Sofia's built environment in recent years. Employee expectations, or at least what employers perceive to be their expectations, have driven successive waves of concentration of business and technology parks in the Southern and South-Eastern peripheries of the city. These spatial dynamics have in turn cemented the car and to some extent the metro as the transport modes which define the commute in the public discourse and local policy, while other types of journeys (e.g. the predominantly pedestrian, bus, trolleybus and tram trips of those who work in the urban core) receiving less attention.

The different possible dynamics between co-workers in various positions in the formal workplace hierarchy discussed above, demonstrate that the commute is not a space free from the hierarchies and power relations which are woven through the workplace. The journey to work is a time-space in which the hierarchies of work continue to be enacted, negotiated, and occasionally subverted. In the next section, I examine how workplace relations shape and are shaped by co-present commutes.

\section{4-2. Arranging and avoiding the shared commute}

This section examines the collective arrangements which go into making travelling together with co-workers possible, and the implications of these arrangements for performing work outside of 
the office, but also for performing care in the relations between co-workers. The section also looks at the opposite set of arrangements - the efforts which go into avoiding traveling to work with co-workers. These often-subtle dynamics, not previously explored in this context, are as influential on practices of working on the go as arrangements of travelling together (Laurier et al., 2008). Similarly, I show that arranging solitary commutes can amount to another dimension of being a considerate co-worker.

Commuting together can involve occasional lifts, regular carpooling, or arranging to travel together to and from work using other modes of transport. Julian, a research participant who worked as a software developer, got a lift home after work during the weeks when his car was undergoing extensive repairs after a collision. Toni, who worked as an administrator in a labour union, had a loose arrangement with a colleague who lived in the same building: they would meet at 8am to travel by metro together, but if one was not there, the other did not have to wait. Several participants described initially 'bumping into' co-workers during their journey, and gradually making more deliberate plans to commute together. These arrangements involved both establishing advance plans, and on-going intricate coordination, and were not always easy to sustain:

I recently found out that [colleague] lives not far from [apartment Emma recently moved to]. So she started giving me a lift home from time to time. Then at one point we started coordinating to leave together in the morning as well. She would text me when she got up, and I would get ready, and we meet at this bus stop on the other side. But it doesn't take any shorter by car compared to metro. In fact, it takes longer. She doesn't take a very direct route; also, a few times we drop her boyfriend off at his job first; then, the traffic. I haven't done it many times, so it hasn't come to irritate me yet. (Emma, graphic designer, works approximately $10 \mathrm{am}$ to $7 \mathrm{pm}$, initially commuted by metro, then carpooling, interviewed February 2014).

Among participants working in the tourism and hospitality sector, the shared commute was more likely to be interpreted as a dimension of mutual care and workplace solidarity. Faced with lower incomes and limited transport options, people working together in bars, restaurants and clubs, and especially those commuting at night, often saw commuting together as a strategy for reducing either costs, or tackling a sense of vulnerability, or both. Travelling together in order to feel safer was especially likely if at least one of the commuters was a woman. This importance of safety considerations to organising collective travel plans can easily be overlooked, when discussions of commuting which focus on '9-to-5' journeys (Collectiu Punt 6, 2017).

Importantly, intricate planning was not always about enabling shared commutes; sometimes, its aim was to prevent them. A number of participants expressed ambivalence or reluctance regarding travelling with co-workers, particularly in the morning:

I just noticed a colleague over there [in the metro carriage]. I sometimes travel with another colleague, who boards in Mladost. If we bump into each other, we travel together and chat. In the morning in particular, it is not always pleasant to chat though. It depends who you end up travelling with. If it's someone you barely know, it's not great, because you end up wondering what to talk about. (Tina, civil servant, car+metro commuter, starts work at 9am sharp, interviewed June 2014)

This position sometimes meant making elaborate, yet subtle arrangements aimed at avoiding travelling together. At the same time, participants felt uneasy about being seen to try to avoid their colleagues. These dynamics were more likely to be described in vague terms, for instance in the case of Emma and Janna, who between 2013 and 2014 took the metro from consecutive stops, travelling to the same office at similar times:

We don't meet on the way to work. We like to travel in different carriages of the metro train - she goes to the back of the train, I take the front. So, we only meet at the platform when we get off. It's just how it happens. (Janna, advertising executive, former car commuter commuting by metro, works approximately $10 \mathrm{am}$ to $7 \mathrm{pm}$, interviewed May 2013) 
While there was no explicit arrangement not to travel together, Emma and Janna both confirmed, in their separate interviews, that they preferred not to travel with others in the morning, and that coincidentally, preferring different ends of the train worked well for them. Maintaining this unspoken arrangement represented showing consideration for each other's, as well as one's own, comfort.

In a relatively small city with a limited metro network 'bumping into' colleagues in the morning rush hour is fairly likely. Thus, quite a few participants were faced with the need to consider the implications of finding themselves sharing their commute with co-workers. These considerations also meant they had to reflect on how they felt about work tasks spilling into their commute. For some, travelling with co-workers would result in the journey becoming a work meeting; for others, it was precisely the need to interact with a co-worker that would erode opportunities to complete work-related tasks during commuting time:

I don't like talking on the metro, so meeting someone I know is not great. It's just too quiet to have a conversation. It's an uneasy situation. You need to talk, but what do you talk about? Especially ifyou haven't seen each other in a long time. You need to share personal things, but it's so uncomfortable. Or if you meet a colleague, and they start talking about work things, in that wholly inappropriate setting! (Tanya, lecturer, former car commuter commuting by metro, variable office hours, interviewed February 2014)

I like my work, it's creative, and I don't mind thinking about a project outside of work. It's a pleasure, I do actually want to think about work sometimes [when commuting]. I can make the most of the quiet time on the metro, I'm alone, and I can come up with something good. (Emma, graphic designer, interviewed November 2013)

As demonstrated by Laurier et al. (2008), managing the interconnections between workplace and commuting practices can be complex, tense and tiring. The authors contrast carpooling with colleagues to picking up a hitchhiker: while offering a ride to a stranger is a one-off gesture which requires the travelling person to manage the situation but does not require any long-term commitment, sharing one's commute with co-workers comes with intricate negotiations of both short-term and long-term implications. Inevitably, what happens during the commute 'seeps into' the times, spaces and relations of work (Bissell, 2014). Importantly, the journeys to work of the research participants in Sofia whose experiences I draw on here, suggest that this holds regardless of whether the commute involves physical co-presence. I turn to this in the next section.

\section{4-3. Situating commuter stress in workplace relations}

It is commonly acknowledged that stress related to commuting influences work. Research has suggested that the frustrations of the journey to work can result in poor concentration, low morale, and higher staff turnover (Wener et al., 2003). In this section, I examine how commuter stress circulates through social relations in the workplace, in the process becoming a shared concern and an opportunity for cooperation.

I don't usually stress out when the traffic is standing still. But what really stresses me out is how bad and how pushy the other drivers around me are. But the jam itself - you can't do anything anyway, so I don't mind. It also does matter that there is no pressure on me to be in the office at a particular time. I don't think I'd be able to cope with a very fixed working time in Sofia. The [people I work with] often arrive all stressed out at work. If you're driving around twenty minutes looking for a parking space, (...) then you also spend twenty minutes telling everyone in the office about your ordeal, and everyone starts empathising. (Julian, software developer, interviewed January 2015)

The complex negotiations of hierarchies, shared rides, and solitude aside, the commute is simply a ubiquitous and important topic of conversation in the workplace. As demonstrated in Julian's description above, the commute makes a recurring appearance at the start of the shift or the office day, is often the foundation of the small talk which precedes formal meetings, and helps create bonds with others over a common, and commonly frustrating, experience. 
Thus, the commute does not stop at the door of the workplace. This has been recognised to some extent in research on commuter stress, or the negative affective appraisal of the commute (Gatersleben and Uzzell, 2007). Topics of commuter stress research have included the difference in stress levels of users of different transport modes (Wener and Evans, 2004), and notably of the impact of commuter stress on worker performance and individual well-being (Wener et al., 2003; Cox et al., 2016). As they originate mostly in psychology, such studies adopt a view of commuter stress as a highly individualised experience, one in which the stress of the journey to work impacts on the recipient-commuter. Considering commuter stress in the context of workplace relations reframes the stressed commuter in terms of their active participation in making mobility-related stress a social and shared experience. In the process, shared or individual approaches to tackling stress may emerge, whether involving new commuting arrangements or simply feeling better through 'telling everyone about your ordeal.' Discussing the frustrations of one's commute with co-workers is more than a coping strategy, however. Through seemingly trivial conversations about overcrowded metro trains, scary pedestrian underpasses, or the lack of parking spaces, commuter stress becomes part of the social relations of the workplace. These moments of sharing can modify the social atmosphere in which work takes place in subtle ways, or it can open up possibilities for other kinds of interaction, be they defined by hierarchical authority, or by small gestures of solidarity:

Towards the end of an event, we usually start talking about transport. People take it seriously. Who is going where, who has a car. Usually no-one [laughs]. Everyone is in the same position, you know, even if we didn't know each other well before, or not at all often. No-one has any money, no-one wants to spend money on a taxi. So, we talk and we try to figure something out together. If a taxi is really needed, because sometimes these events are in the middle of nowhere, then I'll make sure there's four of us to a taxi! [laughs] (Ivelina, model, mostly walks and takes public transport, work hours and locations vary, interviewed January 2018).

This tracing of commuter stress as it circulates through the social interactions of the workplace has implications for how the commute is understood. It contributes another dimension to the problematising of the commuter as a bounded, individual subject, a conceptualisation some of the limitations of which I highlighted at the start of the paper. Relatedly, it challenges the understanding of the erosion of commuter well-being as the quantitative accrual of stressful commuting experiences to an individual. Understanding how, over the long term, commuter stress is shared and coped with by people working together, can contribute to new and more distributed conceptualisations of well-being more broadly (Schwanen and Atkinson, 2015). Future research on this topic could develop interdisciplinary, multifaceted and social framings of how commuting, stress, well-being, and workplace relations, are continuously woven together. Greater attention to commuter stress and well-being, and their collective nature in particular, can help shape measures such as workplace mobility plans, which currently rely on a limited definition of the social and environmental impacts of commuting.

\section{Discussion and conclusion}

In this paper, I have aimed to demonstrate a range of ways in which commuting is embedded in workplace social relations. On one hand, the commute is shaped by workplace relations in both formal and informal ways, sometimes through written workplace mobility plans, but often through the more or less explicit demands which employers place on workers' commuter arrangements, or through the various ways in which employees draw on relations with coworkers as a way of making the commute easier, safer or more affordable. On the other hand, the commute is not restricted to a compartmentalised timespace of being on the move, but is present in the social interactions of the workplace. This may mean making shared plans for the journey home during working hours, or discussing the stressful experiences of morning traffic jams while easing into the tasks for the day. 
To date, mainly positivist and normative theoretical frameworks have informed conceptualisations of the way commuting and workplace social relations may be connected. Such research has focused on employer mobility measures, such as workplace sustainable mobility plans, and on quantifying the impact of commuter stress on work performance and worker wellbeing. The discussion presented above attends to workplace relations - a concept which includes formal and informal interactions, and both systematic and ad-hoc engagements - as a way of highlighting the limitations of these existing approaches to conceptualising the commuter. Understanding the link between the journey to work, and workplace relations, in its many guises and multiple directions, problematises the idea of commuter travel behaviours as based in individual bounded rationality, while at the same time contributing to research which seeks to challenge the compartmentalisation of social life into separate domains such as work, travel and home.

Thus, the paper contributes to understanding the social context in which everyday mobility in general, and commuting in particular, takes place. This contribution extends existing work on the role of household relations in everyday mobility. To some extent, the reliance in the research data on journeys to a specific place of paid work, reproduces the dominant in transport research 'A to $\mathrm{B}^{\prime}$ view of commuting. However, I have aimed to complicate this by drawing attention to the diversity of the research participants' commuting experiences, including those of shift workers in tourism and hospitality and flexible workers, alongside those of 9-to-5 employees. Further research is needed to explore the social relations of commuting in contexts such as unpaid work, volunteering and civil society groups, but also in connecting the social setting of the commute to its spatial context. While it has not been the aim of this paper to compare peripheral and centrally located workplaces, it is clear that workplace social relations are entangled in the proliferation of well-paid jobs on the Southern edges of Sofia, reflecting the broader links between commuting, transport infrastructure and the built environment. The suburbanisation of IT work has been hastened by growing automobility and has exacerbated it in turn, but it has also both shaped and been shaped by the changing priorities of public transport investment. Thus, the many new metro stations in Sofia's Southern and South-Eastern outskirts have often come at the expense of muchneeded renewal of surface level public transport. As a result, the cross-town commute as the 'definitive' Sofia commute has become increasingly self-fulfilling, increasingly shifting local urban and transport planning priorities away from the dense and mixed-use urban core.

Thus, the multiple, both direct and subtle, ways in which workplace relations shape commuting practices, and vice-versa, have important implications for policy and practice. First, given the changing nature of work, it is increasingly important to explore the social and material mechanisms through which flexible, temporary, remote and hub-based work is reshaping everyday mobility for some, but not others (Parry et al., 2005). Second, as the paper demonstrates, workplace relations play a significant role in the way the economic costs, meanings, affects and interactions of commuting, are negotiated. Attending to workplace relations can help think critically about the effectiveness of employer and government measures intended to curb the impact of commuting on individuals, social groups and urban environments. The social relations which stem from the workplace should be explored further for the openings they create to shape urban mobility systems in ways which foster well-being, social inclusion, and environmental sustainability.

\section{References}

Adams, J. (1981) Transport Planning: Vision and Practice. London: Routledge and Kegan Paul.

Barnfield, A. (2016) Experiencing post-socialism: Running and urban space in Sofia, Bulgaria. European Urban and Regional Studies, 24(4), pp. 1-13..

Barnfield, A. and Plyushteva, A. (2016) Cycling in the post-socialist city: On travelling by bicycle in Sofia, Bulgaria. Urban Studies, 53(9), pp. 1822-1835. 
Beige, S. and Axhausen, K.W. (2012) Interdependencies between turning points in life and long-term mobility decisions. Transportation, 39(4), pp. 857-872.

Ben-Elia, E. and Ettema, D. (2011) Rewarding Rush-hour Avoidance: A Study of Commuters' Travel Behavior. Transportation Research Part A: Policy and Practice, 45, pp. 567-582.

Berman, E.M., West, J.P., and Richter, Jr., M.N. (2002) Workplace relations: Friendship patterns and consequences (according to managers). Public Administration Review, 62(2), pp. 217-230.

Bissell, D. (2010) Passenger mobilities: Affective atmospheres and the sociality of public transport. Environment and Planning D, 28, pp. 270-289.

Bissell, D. (2014) Encountering stressed bodies: Slow creep transformations and tipping points of commuting mobilities. Geoforum, 51, pp. 191-201.

Bissell, D. (2018) Transit Life: How Commuting Is Transforming Our Cities. Cambridge, MA: MIT Press.

Cairns, S., Newson, C. and Davis, A. (2010) Understanding successful workplace travel initiatives in the UK. Transportation Research Part A: Policy and Practice, 44(7), pp. 473-494.

Chatterjee, K. and Scheiner, J. (2015) Understanding changing travel behaviour over the life course: Contributions from biographical research. In: Proceedings from 14th International Conference on Travel Behaviour Research, Windsor, UK, 19-23 July 2015, Available at http://eprints.uwe.ac.uk/28177, Accessed 22 November 2016.

Chatterjee, K., Goodwin, P., Schwanen, T., et al. (2018) Young People's Travel - What's Changed and Why? Review and Analysis. Report to Department for Transport. Bristol: University of the West of England.

Cohen, R.L. (2008) Work relations and the multiple dimensions of the work-life boundary: Hairstyling at home in: Warhurst, C., Eikhof, D.R. and Haunschild, A. (eds.) Work less, live more? Critical Perspectives in Work and Employment, London: Palgrave MacMillan.

Collectiu Punt 6 (2017) Nocturnas: The Everyday Life of Women Nightshift Workers in the Barcelona Metropolitan Area. Barcelona: Collectiu Punt 6.

Collins, A.M., Hislop, D. and Cartwright, S. (2016) Social support in the workplace between teleworkers, office-based colleagues and supervisors. New Technology, Work and Employment 31(2), pp. 161-175.

Cox, T., Houdmont, J. and Griffiths, A. (2006) Rail passenger crowding, stress, health and safety in Britain. Transportation Research Part A: Policy and Practice 40(3), pp. 244-258.

Döring, L., Albrecht, J., Scheiner, J., et al. (2014) Mobility biographies in three generations socialization effects on commute mode choice. Transportation Research Procedia 1(1), pp. 165-176.

Ellegård, K. and Svedin, U. (2012) Torsten Hägerstrand's time-geography as the cradle of the activity approach in transport geography. Journal of Transport Geography 23, pp. 17-25.

Enoch, M. (2012) Sustainable Transport, Mobility Management and Travel Plans. Aldershot: Ashgate. 
Eurostat (2018a) Population on 1 January by age group, sex and NUTS 3 region. Brussels: European Commission. Available at https://ec.europa.eu/eurostat/data/database Accessed 20 November 2018.

Eurostat (2018b) Population on 1 January by age groups and sex - cities and greater cities. Brussels: European Commission. Available at https://ec.europa.eu/eurostat/data/database Accessed 4 October 2018.

Gatersleben, B. and Uzzell, D. (2007) Affective appraisals of the daily commute: comparing perceptions of drivers, cyclists, walkers, and users of public transport. Environment and Behavior 39(3), pp. 416-431.

Ge, J., Polhill, J.G. and Craig, T.P. (2018) Too much of a good thing? Using a spatial agent-based model to evaluate "unconventional" workplace sharing programmes. Journal of Transport Geography 69, pp. 83-97.

Gil Solá, A. (2016) Constructing work travel inequalities: The role of household gender contracts. Journal of Transport Geography 53, pp. 32-40.

Grozdanov, V. (2011) Urban Mobility Problems in Sofia. In: Proceedings from the 20th International Conference Transport 2011, Sofia.

Hagerstrand, T. (1973) The Domain of human geography, in Chorley, R. (ed.) Directions in Geography. London: Methuen.

Hamilton, K. and Jenkins, L. (2000) A gender audit for public transport: A new policy tool in the tackling of social exclusion. Urban Studies 37(10), pp. 1793-1800.

Hanson, S. (2010) Gender and mobility: new approaches for informing sustainability. Gender, Place \& Culture 17(1), pp. 5-23.

Hirt, S. (2012) Iron Curtains: Gates, Suburbs, and Privatization of Space in the Post-Socialist City. Hoboken, N.J: Wiley \& Sons.

Jain, J. and Lyons, G. (2008) The gift of travel time. Journal of Transport Geography 16(2): 81-89.

Jarvis, H. (1999) The tangled webs we weave: Household strategies to coordinate home and work. Work, Employment and Society 13(2), pp. 225-247.

Jirón, P. and Imilan, W.A. (2015) Embodying flexibility: Experiencing labour flexibility through urban daily mobility in Santiago de Chile. Mobilities 10(1), pp. 119-135.

Jirón, P.A., Imilan, W.A. and Iturra, L. (2016) Relearning to travel in Santiago: the importance of mobile place-making and travelling know-how. cultural geographies 23(4), pp. 599-614.

Lanzendorf, M. (2010) Key events and their effect on mobility biographies: the case of childbirth. International Journal of Sustainable Transportation 4(5), pp. 272-292.

Laurier, E. and Lorimer, H. (2012) Other ways: Landscapes of commuting. Landscape Research 37, pp. 207-224.

Laurier, E., Lorimer, H., Brown, B., et al. (2008) Driving and 'passengering': notes on the ordinary organization of car travel. Mobilities 3(1): 1-23. 
Law, R. (1999) Beyond 'women and transport': towards new geographies of gender and daily mobility. Progress in Human Geography 23(4), pp. 567-588.

Lyons, G. and Chatterjee, K. (2008) A human perspective on the daily commute: Costs, benefits and trade-offs. Transport Reviews 28(2): 181-198.

Manderscheid, K. (2013) Criticising the solitary mobile subject: Researching relational mobilities and reflecting on mobile methods. Mobilities 9(2), pp. 188-219.

McDowell, L. (2008) Thinking through work: complex inequalities, constructions of difference and trans-national migrants. Progress in Human Geography 32(4), pp. 491-507.

Middleton, J. (2011) 'I'm on autopilot, I just follow the route': Exploring the habits, routines and decision-making practices of everyday urban mobilities. Environment and Planning A 43(12), pp. 2857-2877.

Mott Macdonald, (2011) Integrated Plan for the Organisation of Mobility in the Territory of the Capital Region: Final report. Sofia: Sofia Municipality.

Nixon, D.V. (2014) Speeding capsules of alienation? Social (dis)connections amongst drivers, cyclists and pedestrians in Vancouver, BC. Geoforum 54, pp. 91-102.

National Statistics Institute (2016) Sofia in Figures 2015. Sofia: National Statistics Institute.

National Statistics Institute (2019) Infostat Database, Available at http://infostat.nsi.bg/infostat, Accessed 20 May 2019.

O'Dell, T. (2009) My soul for a seat: Commuting and the routines of mobility, in Shove, E., Trentmann, F., and Wilk, R. (eds.) Time, Consumption and Everyday Life: Practice, Materiality and Culture. Oxford: Berg.

Parry, J., Taylor, R., Pettinger, L., et al. (2005) Confronting the challenges of work today: new horizons and perspectives. The Sociological Review 53(2_suppl), pp. 1-18.

Pettinger, L. (2005) Friends, relations and colleagues: The blurred boundaries of the workplace. The Sociological Review 53(2_suppl), pp. 37-55.

Plyushteva, A. (2016) Commuting with new transport infrastructure: Change, cost and comfort on the Sofia metro extension. London: University College London.

Plyushteva, A. (2019) Commuting and the urban night: Nocturnal mobilities in tourism and hospitality work. Journal of Policy Research in Tourism, Leisure and Events 11(3), pp. 407421.

Plyushteva, A. (2019) Predictability and propinquity on the Sofia Metro: Everyday metro journeys and long-term relations of transport infrastructuring, in Tuvikene, T., Sgibnev, W., and Neugebauer, C. (eds.) Post-Socialist Urban Infrastructures. London: Routledge.

Plyushteva, A. and Schwanen, T. (2018) Care-related journeys over the life-course: Thinking mobility biographies with gender, care and the household. Geoforum, 97, pp. 131-141. 
Pooley, C.G., Horton, D., Scheldeman, G., Tight, M., Jones, T., Chisholm, A., Harwatt, H. and Jopson, A. (2011) Household decision-making for everyday travel: a case study of walking and cycling in Lancaster (UK), Journal of Transport Geography, 19(6), pp. 1601-1607.

Pratt, G. and Hanson, S. (1991) On the links between home and work: Family-household strategies in a buoyant labour market. International Journal of Urban and Regional Research 15(1), pp. $55-74$.

Pratt, G. and Hanson, S. (1993) Women and work across the life course: Moving beyond essentialism, in Kat,z C. and Monk, J.J. (eds.) Full Circles: Geographies of Women over the Life Course. London/New York: Routledge.

Rau, H. and Sattlegger, L. (2018) Shared journeys, linked lives: a relational-biographical approach to mobility practices. Mobilities 13(1), pp. 45-63.

Roby, H. (2010) Workplace travel plans: past, present and future. Journal of Transport Geography 18(1), pp. 23-30.

Roelofsen, M. (2018) Performing "home" in the sharing economies of tourism: the Airbnb experience in Sofia, Bulgaria. Fennia - International Journal of Geography 196(1), pp. 24-42.

Roy, D.F. (1959) "Banana time": Job satisfaction and informal interaction. Human Organization 18(4), pp. 158-168.

Schwanen, T. (2006) On 'arriving on time', but what is 'on time'? Geoforum 37(6), pp. 882-894.

Schwanen, T. (2007) Gender differences in chauffeuring children among dual-earner families. The Professional Geographer 59(4), pp. 447-462.

Schwanen, T. and Atkinson, S. (2015) Geographies of wellbeing: an introduction. The Geographical Journal 181(2), pp. 98-101.

Shen, Y., Kwan, M.-P. and Chai, Y. (2013) Investigating commuting flexibility with GPS data and 3D geovisualization: a case study of Beijing, China. Journal of Transport Geography 32, pp. 1-11.

Sias, P. (2012) Workplace relationships, ostracism, and isolation in Omdahl, B.L. and Harden, F. J. (eds.) Problematic Relationships in the Workplace. New York: Peter Lang.

Sofia Municipality (2016) Програма за развитие на велосипедния транспорт на територията на столична община [Programme for the development of cycling on the territory of the Capital Municipality] 2016-2019. Sofia: Sofia Municipality.

Thrift, N. and Pred, A. (1981) Time-geography: a new beginning. Progress in Human Geography 5(2), pp. 277-286.

Van Malderen, L., Jourquin, B., Thomas, I., Vanoutrive, T., Verhetsel, A. and Witlox, F. (2012) On the mobility policies of companies: What are the good practices? The Belgian case. Transport Policy 21, pp. 10-19.

Vannini, P. (2011) The techne of making a ferry: A non-representational approach to passengers' gathering taskscapes. Journal of Transport Geography 19, pp. 1031-1036. 
Vision for Sofia (2018) Step 2: Report on the Theme of Transport. Sofia: Vision for Sofia/Sofia Municipality, Available from www.vizia.sofia.bg, Accessed 20 April 2019.

Wener, R., Evans, G., Phillips, D., and Nadler, N. (2003) Running for the 7: 45: The effects of public transit improvements on commuter stress. Transportation 30(2), pp. 203-220.

Wener, R. and Evans, G. (2004) The Impact of Mode and Mode Transfer on Commuter Stress: the Montclair Connection, Trenton, NJ: New Jersey Department of Transportation or the Federal Highway Administration.

Wheelock, J. and Oughton, E. (1996) The household as a focus for research. Journal of Economic Issues 30(1), pp. 143-159.

Wilson, H. (2011) Passing propinquities in the multicultural city: The everyday encounters of bus passengering. Environment and Planning A 43, pp. 634-649.

\section{Endnotes}

' Own calculation based on data from Vision for Sofia (2018:113) and Eurostat (2018b). 